\title{
Study on the Current Situation of Education in Western Wind Instruments in China
}

\author{
Wei Han
}

School of music, Jimei University, Fujian, China, 361000

Keywords: wind music education; development; popularization

\begin{abstract}
Music, as a main form of the inheritance and recording of human civilization, has become an indispensable part of the development of human history, which contains rich connotations of human spiritual civilization. Nowadays, music education has also become an important content of quality education. It cultivates students' aesthetic ability, molds people's sentiments, and promotes students' perfect personality. Nowadays, the rapid development of society and economy has greatly promoted the development of music education, especially under the background of the continuous deepening of new curriculum reforms, which has promoted the effective implementation of the strategy of rejuvenating the country through science and education, and has also promoted music education in modern education. The music education in the country has many years of development history, and it also occupies a very important position in the modern education system. This paper discusses the issues related to the popularization and development of the city in light of the development of music education.
\end{abstract}

\section{Introduction}

The management of band music and the masses of the orchestra's activities are important classrooms for cultivating the quality education of young people and cultivating team spirit. They are also examples of the quality of the people. At present, there are thousands of non-professional orchestras in the country. According to statistics, there are currently more than 5,000 bands in the mainland China and more than 500,000 participants. There are about 500 Beijing, more than 140 in Shanghai, more than 140 in Guangzhou, more than 140 in Guangzhou, more than 110 in Shenzhen, more than 100 in Daxinganling, and dozens in Tianjin, Chongqing, Xi'an, Shenyang, Dalian, etc., Nanchang, Hangzhou, Zhuhai, and Zhengzhou. In Wuhan, Nanjing, Guilin and other places, there are also new developments of the band. With the capital and open coastal cities as the first, many outstanding orchestras stand out. The ensemble level and organizational management of the orchestra have reached the domestic advanced level.

\section{Development of China's Wind Music and Bands}

The development of early non-professional band organizations was first established in the early Qing Dynasty in China. The invasion of imperialism also led to the first entry of foreign pipe music into China. At the time, the missionaries moved extensively in some southern regions of China and promoted The development of music between different cities, such as Beijing, Xiamen, Guangzhou, Tianjin, Harbin and other cities, is also the primary stage of the development of wind power in China. In the 1920s, various cities started to build wind instruments in universities, such as Tsinghua University and Nanling University in Guangzhou. Since then, they have begun to develop in the field of education in China [1].

The relatively rapid development of the school's school band team was established after the founding of New China. At this time, the orchestra has already achieved certain development in China. In some universities, there are developments of the orchestra, such as Beijing Normal University. Beijing Aviation College, Tianjin University, Nankai University and so on. At this time, the student band music team was active in many activities on and off campus. At the same time, it became the main position for the school to carry out moral education. 
The development of corporate orchestras is mainly concentrated in the period before liberation. Except for large and medium-sized cities in Guangdong Province and the South, other regions have shown some lag in the development of the orchestras of companies and factories. At that time, the development of the factory enterprise orchestra was given full attention by the leaders. The enthusiasm of the employees to carry out the orchestra was also high. At that time, Shanghai Trolley No. 2 Plant, Luoyang Heavy Machinery Factory, Guangzhou Shipyard, etc., all carried out a wealth of pipe orchestras. activity. With the passage of time, factory and company companies in Zibo, Tianjin, Zhengzhou, and Tangshan in Shandong Province have also increasingly carried out wind band activities[2]. The basic training chart for the band is as follows.

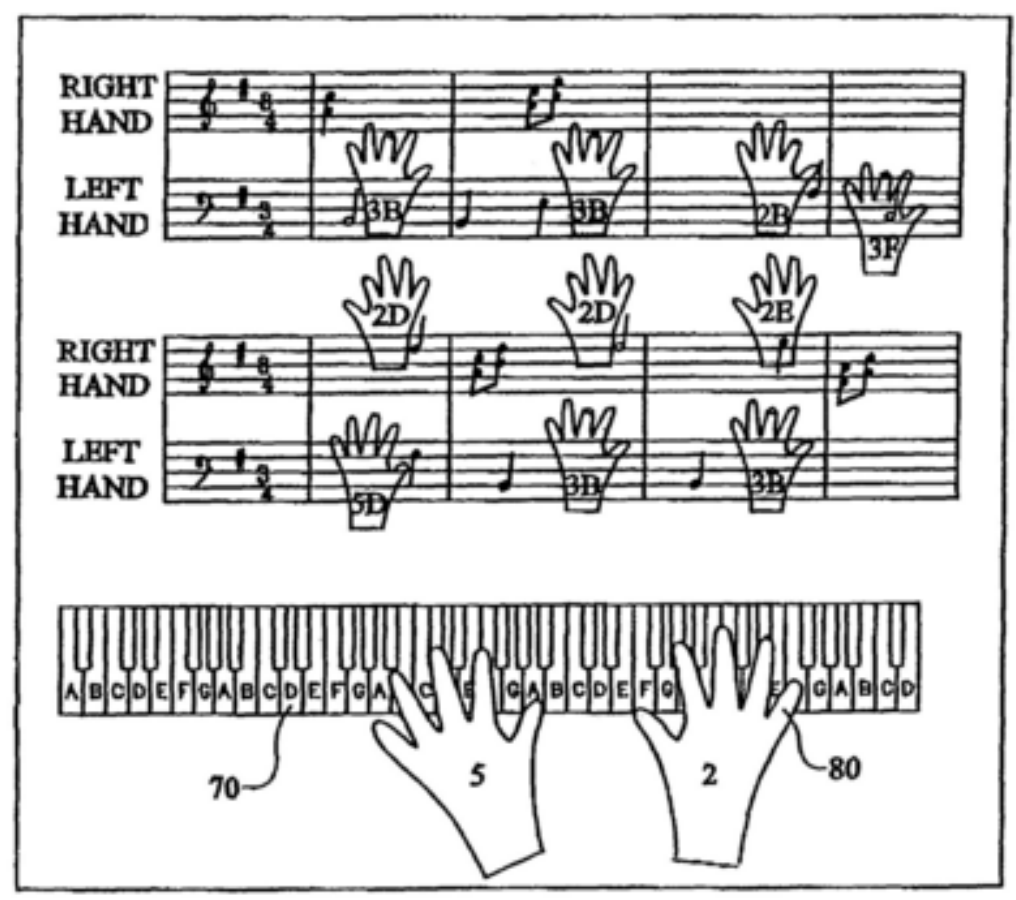

Fig.1 Band Orchestra Basic Training

\section{Strategies for the Development of Wind Music Education in China}

\subsection{Identify clear teaching objectives and teaching tasks for wind music education}

Extra-curricular life has a very important role in the cultivation of students' own creativity. A variety of extra-curricular activities can inspire students' aesthetic taste. At the same time, it also promotes the cultivation of students' comprehensive qualities in music education. In the management of band music, it must be clear. Teaching goals and teaching tasks can make the activities more targeted. At present, we have seen that some of the students' self-organized band performance teams are organized and arranged by the students themselves. In this process, students' coordination and organization skills can also be greatly improved. In addition to their own professional courses, students mostly have a wide range of interests. If they can develop the music education into the interests of students, they will have more interest in participating in the rehearsals and performances of the band. This will enable students to In his spare time, he has strengthened the learning of wind music and promoted the enrichment of students' after-school life. At the same time, he also improved the teaching quality of wind music education. At present, in larger cities such as Beijing and Shanghai, many institutions and elementary and middle schools have established orchestras or bands. This is exactly what the current student's music quality embodies. These band music groups regularly perform various performances and strengthen mutual exchanges and cooperation, which is also an effective way to promote the rapid development of China's pipe music education[3]. Chinese students' music quality development formula is as follows. 


$$
\begin{aligned}
& s(\beta)=\sum_{t}\left(y_{t}-f\left(x_{t}, \beta\right)\right)^{2} \\
& \frac{\partial S(b)}{\partial b}=\sum_{t} 2\left(y_{t}-f\left(x_{t}, b\right)\right) \frac{\partial f\left(x_{t}, b\right)}{\partial b}=0
\end{aligned}
$$

\subsection{Establish and improve the management system of wind music education}

In school activities, schools should clearly define the teaching objectives and teaching contents of the pipe music education, actively organize students to participate in various orchestra activities, and effectively enrich the students' second class. But at the same time, there are also some problems. Because the students of the orchestra often come from different professions, there is a certain degree of difficulty in the process of music education. The daily rehearsal activities will also become more difficult due to the different foundations of students. How effective are they? To overcome this series of problems, it is necessary to continuously promote the improvement of the management system in order to be able to rationally arrange teaching and practice, and to encourage students to actively and effectively invest in training. In general, the orchestra's management system should include orchestra disciplines, teacher-student attendance systems, rewards and penalties, distribution of instrumental musical scores, etc. The improvement of the management system plays an important role in promoting the development of piped music education, not only to ensure Strictly abide by the rules of the system in daily activities, and at the same time, promote the improvement of relevant incentive mechanisms, attract and encourage more students to participate in the art activities of wind instruments, and give students a great deal of space for autonomy so as to promote the overall quality of students. overall enhancement. Musical instrument management weights are as follows.

Table1. Musical instrument management weights

\begin{tabular}{ccccc}
\hline Index & $\begin{array}{c}\text { Orchestra } \\
\text { discipline }\end{array}$ & $\begin{array}{c}\text { Teacher-student } \\
\text { attendance system }\end{array}$ & $\begin{array}{c}\text { Rewards and } \\
\text { penalties }\end{array}$ & $\begin{array}{c}\text { Score distribution } \\
\text { system }\end{array}$ \\
\hline Weight & 0.4195 & 0.1225 & 0.2650 & 0.1930 \\
\hline
\end{tabular}

\subsection{Strengthen the construction of teaching staff of wind music education}

Regardless of the teaching activities under any model, to ensure that it can be successfully carried out, it is necessary to have a solid teaching force, which is also a necessary condition for the promotion of the development of pipe music education. The teachers in our country are relatively weak in the management of pipe music, and the quality of students in the professional music management also shows a greater difference between the two ends. This has a great relationship with the lack of teachers. To solve this problem, on the one hand, The country needs to balance our country's excellent faculty resources so that it can achieve balanced development in different cities. This has an important role in improving the overall educational quality of pipe music education. On the other hand, it is necessary to strengthen the construction of professional music teachers' own professional knowledge. As a music teacher, it is necessary to continuously strengthen their mastery of professional knowledge through various learning and training. At the same time, they can participate in the performance of the student's tube band. Great promotion of student professional skills. Domestic schools should actively participate in exchange activities at home and abroad, broaden their horizons, introduce advanced foreign knowledge and teaching concepts through the development of various exchange activities, and promote the rapid development of China's pipe music education [4].

\section{Summary}

The music education is an indispensable part of music education. The extensive development of 
wind music education has become one of the main ways to cultivate students' artistic accomplishment. Under the current music education model in our country, the popularity of pipe music education is promoted. Through the establishment of the orchestra, students' self-confidence is fostered, the development of students' cooperative awareness is promoted, and there is an irreplaceable role of other forms of education in the promotion of students' overall quality. The pipe ensemble has a beautiful sound line and a loud sound that can deduce its full-featured musical works in different occasions. It is of great significance in advancing the development of art education in China.

\section{References}

[1] Xiao-Rong Dong, Hua-Xun Zhang,Mu-Min Cao,Dong-Ni Wu, Jing Xia. [Survey of epidemic status of paragonimiasis in western mountainous areas in Hubei Province]. [J]. Zhongguo xue xi chong bing fang zhi za zhi = Chinese journal of schistosomiasis control,2017,29(5).

[2] Anthony Blash, Connie L. Saltsman,Condit Steil. A National Survey on the Current Status of Informatics Residency Education in Pharmacy[J]. Currents in Pharmacy Teaching and Learning,2017.

[3] Mira Palonen MNSc, Marja Kaunonen PhD, Päivi Åstedt - Kurki PhD. Family involvement in emergency department discharge education for older people[J]. Journal of Clinical Nursing,2016,25(21-22).

[4] Xin Zeng, Xiaoni Zhong, Bin Peng, Yan Zhang, Cuie Kong, Xiyao Liu, Ailong Huang. Prevalence and associated risk characteristics of HIV infection based on anal sexual role among men who have sex with men: a multi-city cross-sectional study in Western China[J]. International Journal of Infectious Diseases,2016,49. 